\title{
A Case Report of Delayed Hemothorax Complicated by Fibrothorax
}

\author{
Tanvi Chokshi ${ }^{1}$, Alexandra Theodosopoulos ${ }^{1}$, Ethan Wilson ${ }^{1}$, Michael Ysit ${ }^{1}$, Sameir Alhadi $^{2}$, Leonard Ranasinghe ${ }^{3^{*}}$ \\ ${ }^{1}$ Second year medical students, California Northstate University, Elk Grove, California, USA \\ ${ }^{2}$ Director of Emergency Department and Emergency Medicine Clerkship Site Director, St. Agnes Medical \\ Center, Fresno, California, USA \\ ${ }^{3}$ Professor and Emergency Medicine Clerkship Director, California Northstate University, Elk Grove, \\ California, USA
}

Corresponding Author: Leonard Ranasinghe, MD

Address: College of Medicine, California Northstate University, 9700 West Taron Drive Elk Grove, California 95757, USA; Tel: 916-496-5072; Email: leonard.ranasinghe@cnsu.edu

Received date: 26 September 2021; Accepted date: 25 October 2021; Published date: 02 November 2021

Citation: Chokshi T, Theodosopoulos A, Wilson E, Ysit M, Alhadi S, Ranasinghe L. A Case Report of Delayed Hemothorax Complicated by Fibrothorax. Asp Biomed Clin Case Rep. 2021 Nov 02;4(3):184-90.

Copyright (C) 2021 Chokshi T, Theodosopoulos A, Wilson E, Ysit M, Alhadi S, Ranasinghe L. This is an openaccess article distributed under the Creative Commons Attribution License, which permits unrestricted use, distribution, and reproduction in any medium provided the original work is properly cited.

\begin{abstract}
Delayed hemothorax is a potentially life-threatening complication of thoracic trauma that should be carefully considered in all patients presenting with thoracic injury. We report a case of delayed hemothorax in a 77-year-old male presenting eleven days' status post multiple right mid- to high-rib fractures. His case was complicated by retained hemothorax after CT-guided chest-tube with subsequent video-assisted tube thoracostomy (VATS) revealing fibrothorax necessitating conversion to open thoracotomy. Known risk factors for development of delayed hemothorax include older patient age, three or more rib fractures, and presence of mid- to high-rib fractures, and should be used in risk stratification of thoracic trauma. Tube thoracostomy is often sufficient in management of delayed hemothorax. In rare cases, hemothoraces can be complicated by retained hemothorax or fibrothorax, which require more invasive therapy and carry greater morbidity and mortality.
\end{abstract}

\section{Keywords}

Delayed Hemothorax, Chest Wall Trauma, Rib Fractures, Fibrothorax, Open Thoracotomy

\section{Introduction}

Delayed hemothorax is a life-threatening complication of thoracic trauma, commonly including rib fractures, that carries significant morbidity $[1,2]$. Delayed hemothorax has been reported to develop 2 hours up until 44 days after initial injury and is therefore an easily missed sequelae of chest trauma [3]. Treatments vary from non-surgical management with tube thoracostomy and thoracentesis to operative intervention, often including video-assisted thoracoscopic surgery [4].
Management is rarely complicated by retained hemothorax, which is defined as retained clots measuring at least $500 \mathrm{~mL}$ or an amount of residual blood that is greater than onethird of the initial blood in the pleural space [5]. Retained blood can irritate the pleura and cause diffuse pleural scarring or pleural adhesions that can encase the lung [6]. This complication known as fibrothorax typically requires more invasive surgical management of thoracotomy [4]. We present a case of delayed large hemothorax 11 days after blunt chest trauma complicated by retained hemothorax with fibrothorax requiring open thoracotomy. 
Citation: Chokshi T, Theodosopoulos A, Wilson E, Ysit M, Alhadi S, Ranasinghe L. A Case Report of Delayed Hemothorax Complicated by Fibrothorax. Asp Biomed Clin Case Rep. 2021 Nov 02;4(3):184-90.

\section{Case Report}

\section{Case Report}

A 77-year-old male with past medical history of lumbar disc disease, prostate adenocarcinoma status post radical prostatectomy, and thyroid cancer status post thyroidectomy, was brought in by ambulance to the emergency department after sustaining a fall from his bicycle. He reported head injury with brief loss of consciousness. Patient had a blood pressure of 131/70 on arrival. Vital signs were otherwise stable, with temperature of $36.5^{\circ} \mathrm{C}$, heart rate of $91 \mathrm{bpm}$, respiratory rate of 16 breaths/minute, blood pressure of $131 / 70 \mathrm{mmHg}$, and pulse oximetry of $98 \%$ on room air. Serial neurologic exams and noncontrast CT scans of head and neck were benign. An x-ray of the right shoulder demonstrates a comminuted, slightly displaced and overriding fracture of the right midclavicle with mild subcutaneous emphysema in the right lower neck region, and multiple right rib fractures (Fig-1).

Further investigation via contrast $\mathrm{CT}$ chest demonstrated mildly displaced fractures of the lateral right $3^{\text {rd }}-8^{\text {th }}$ ribs with small rightsided apical pneumothorax. Patient's laboratory studies revealed a mild anemia with hemoglobin value of 10.7 (12.0) $\mathrm{gm} / \mathrm{dL}$ and hematocrit of $32.0 \%(35.3 \%)$. CBC and metabolic panel were otherwise benign. He had considerable pain with respiration. Normal oxygen

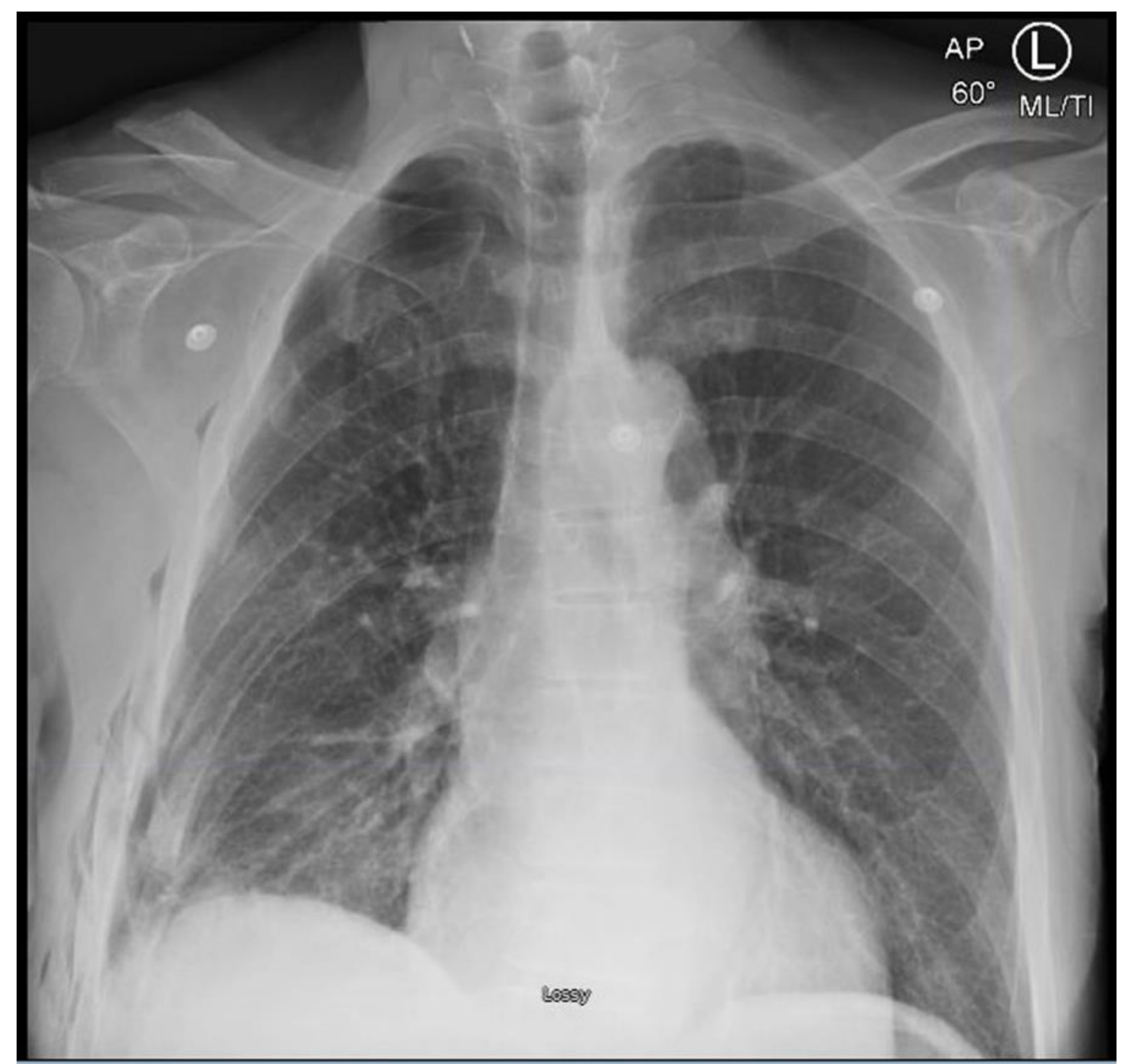

Fig-1:

Initial chest $x$-ray, demonstrating multiple right rib fractures, fracture of the right clavicle, and 10\% right pneumothorax with subcutaneous emphysema. 
Citation: Chokshi T, Theodosopoulos A, Wilson E, Ysit M, Alhadi S, Ranasinghe L. A Case Report of Delayed Hemothorax Complicated by Fibrothorax. Asp Biomed Clin Case Rep. 2021 Nov 02;4(3):184-90.

\section{Case Report}

saturation was maintained via nasal cannula oxygen therapy. He was admitted to hospitalist service for pain control and orthopaedic consultation. His medications included aspirin 81mg daily, which was halted throughout hospital stay. He tolerated incentive spirometry and oxygen saturation was $98 \%$ on room air at discharge three days later. The patient was discharged with $2 \mathrm{~L}$ home oxygen via nasal cannula (Fig-2). He was instructed to resume daily aspirin therapy and take acetaminophen-hydrocodone 325 mg-10 mg as needed for pain.

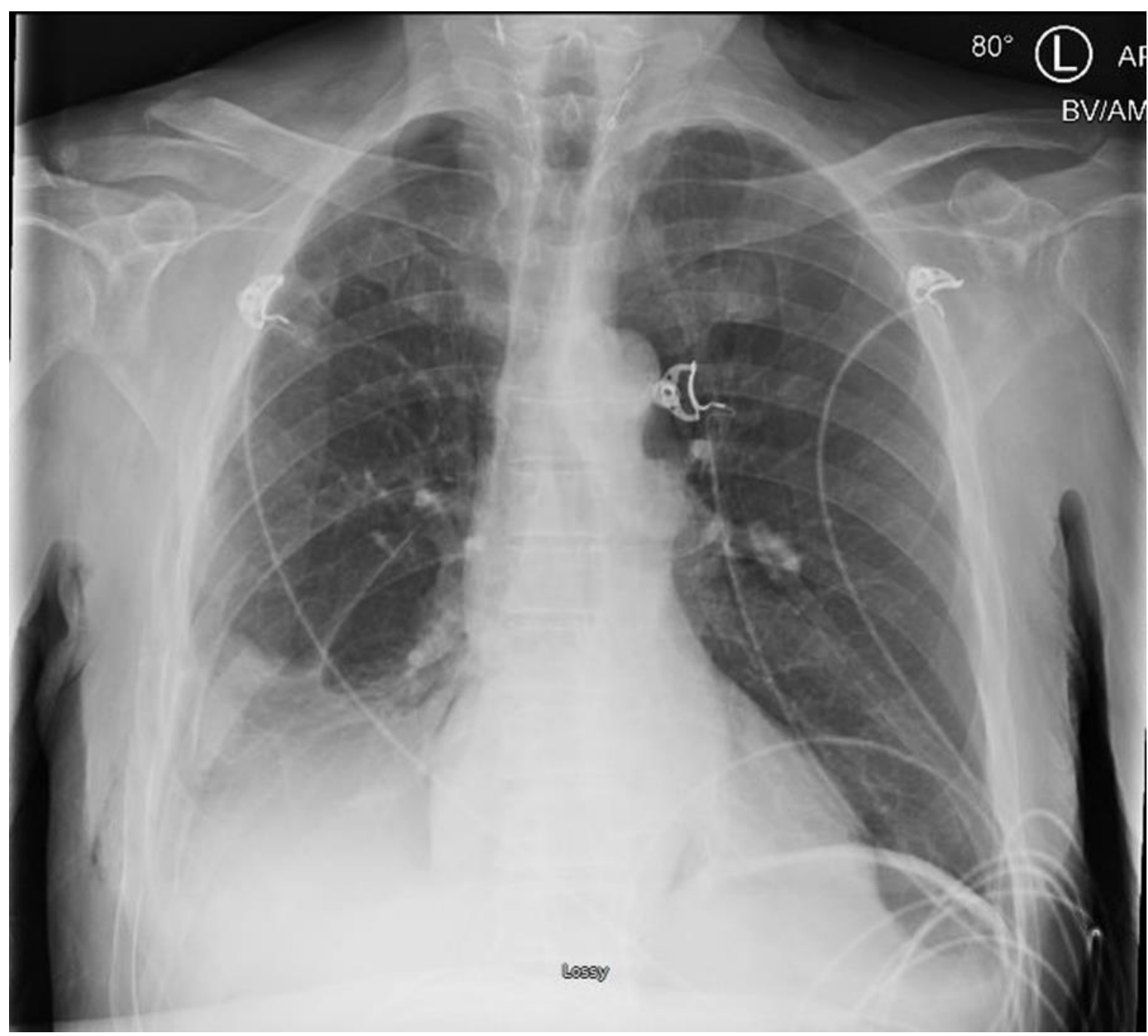

Fig-2:

Follow up chest x-ray upon discharge, showing decreased size of pneumothorax, decreasing right pleural effusion, and decreasing subcutaneous emphysema.

Eleven days following initial trauma, the patient was brought in by ambulance with acute onset dyspnea that woke him from his sleep one hour prior to arrival (Fig-3). He had generalized weakness and light headedness throughout the day, and as a result was unable to ambulate by late evening. Patient's oxygen saturation was noted to be $83 \%$ on his home pulse oximeter and called EMS. He also reported having slept upright since discharge from hospital. There were no new falls or trauma. Initial vital signs in ED showed blood pressure $87 / 53 \mathrm{mmHg}$, heart rate of 72 beats per minute, respiratory rate 18 breaths per minute, oxygen saturation $99 \%$ of $2 \mathrm{~L}$ nasal cannula. The patient's physical exam revealed severely diminished breath sounds at the right lung base. His initial laboratory studies showed significant anemia with hemoglobin of $8.8 \mathrm{gm} / \mathrm{dL}$ and hematocrit of $23.4 \%$. He also had elevated d-dimer 2,270 DDU ng/mL and lactate 2.44 $\mathrm{mmol} / \mathrm{L}$. Troponin I, BNP, as well as the remainder of the metabolic panel and $\mathrm{CBC}$ were unremarkable. CT 
Citation: Chokshi T, Theodosopoulos A, Wilson E, Ysit M, Alhadi S, Ranasinghe L. A Case Report of Delayed Hemothorax Complicated by Fibrothorax. Asp Biomed Clin Case Rep. 2021 Nov 02;4(3):184-90.

\section{Case Report}

angiography of chest demonstrated a large, loculated, right hemothorax. His repeat $\mathrm{CBC}$ showed a hemoglobin of $7.8 \mathrm{gm} / \mathrm{dL}$ and a hematocrit of $23.4 \%$.
Patient was stabilized with intravenous fluids and transfusion with 2 units of PRBCs, and was admitted to the intensive care unit.

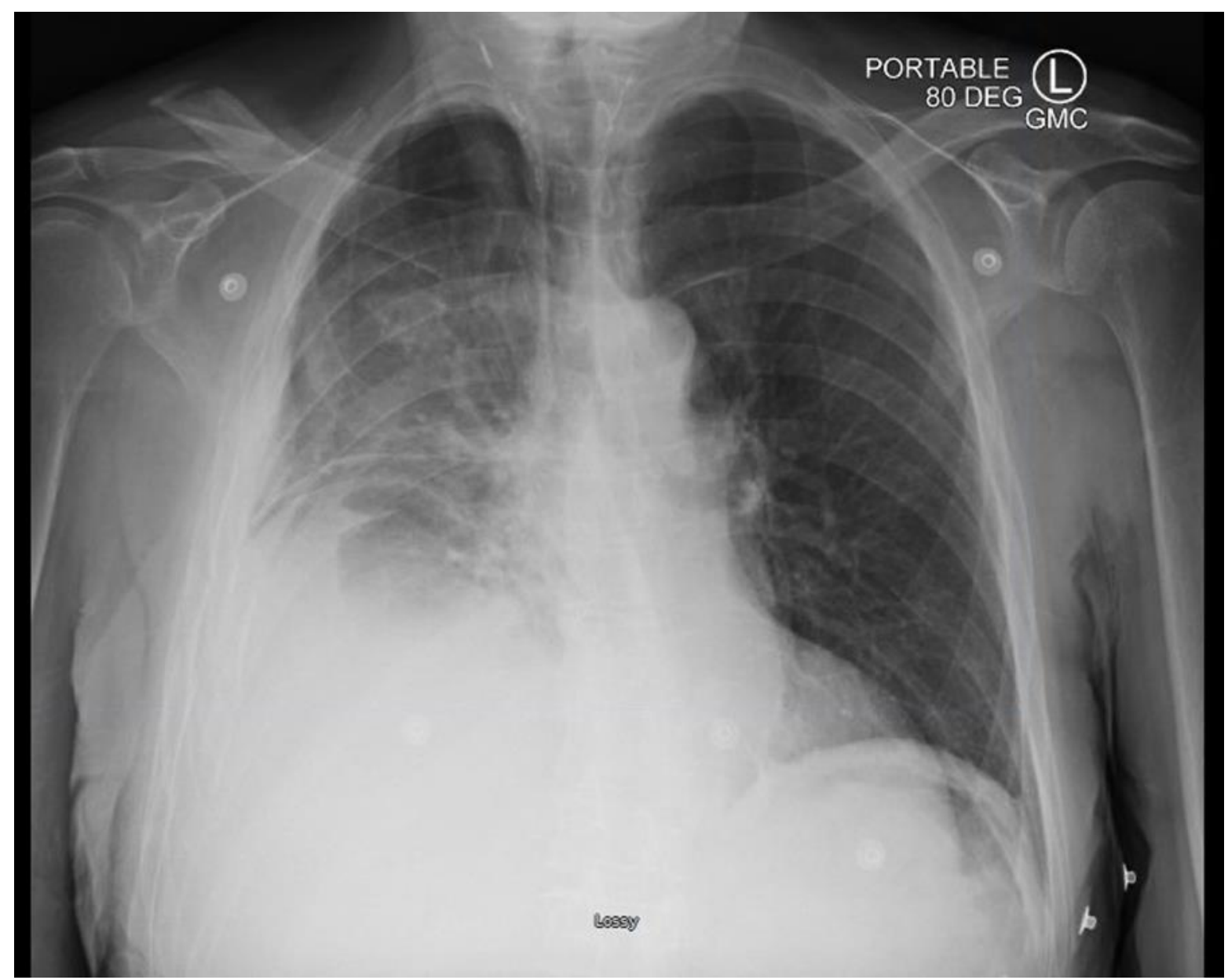

Fig-3:

Chest $x$-ray performed in emergency department eleven days following initial trauma, demonstrating moderate to large volume right-sided effusion with consolidation pneumonitis atelectasis. Interval worsening compared to prior study.

A right-sided CT-guided chest-tube was placed draining $3 \mathrm{~L}$ of serosanguinous fluid. Follow-up CT chest demonstrated retained right loculated hemothorax and videoassisted thoracoscopic surgery (VATS) was performed on the third day of admission. VATS showed adhesions with fibrothorax of right middle and lower lobes, and hemothorax in right pleural space. Procedure was converted to an open thoracotomy for evacuation of the hemothorax, decortication, repair of rib fractures and placement of two chest tubes (Fig-4). The patient remained hemodynamically stable without recurrence of pneumothorax or hemothorax, and was discharged six days following procedure.

\section{Discussion}

Delayed hemothorax should be carefully considered and anticipated in all patients presenting with thoracic injuries. Detection of delayed hemothorax in these patients is hindered by conflicting literature regarding the necessity of follow-up imaging studies $[7,8]$ and perception of its rarity. The incidence of delayed hemothorax in patients with thoracic trauma has been reported between $7.4-11.8 \%$ in prior prospective studies $[9,10]$. This is considerably greater than the incidence of delayed pneumonia (4\%), an often considered sequelae of rib fracture [11,12], arguing for greater consideration of delayed hemothorax in thoracic trauma. 
Citation: Chokshi T, Theodosopoulos A, Wilson E, Ysit M, Alhadi S, Ranasinghe L. A Case Report of Delayed Hemothorax Complicated by Fibrothorax. Asp Biomed Clin Case Rep. 2021 Nov 02;4(3):184-90.

\section{Case Report}

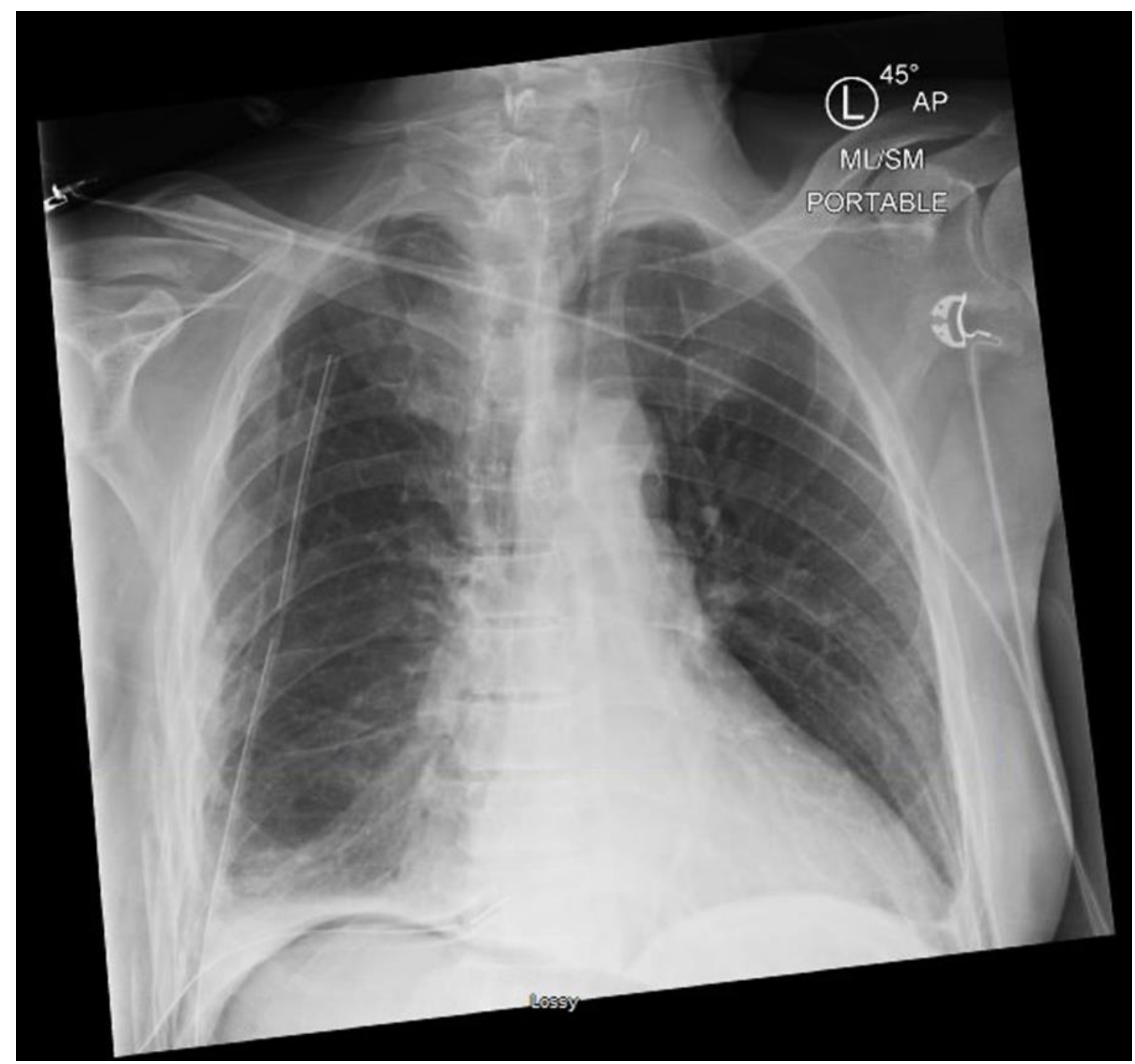

Fig-4:

Postoperative chest $x$-ray, showing interval placement of right apical and right basilar chest tubes. There is a notable decrease in size of the left-sided pleural effusion and re-expansion of the right lung. Left hemithorax is clear.

Clinical decision rules and consideration of patientspecific factors should guide patient management in the setting of thoracic trauma with rib fracture. In particular, elderly patients and patients with multiple or displaced rib fractures [13] are at significantly higher risk for development of delayed hemothorax. Émond et al. highlighted the importance of risk factor identification within chest trauma patients [9]. This 2017 prospective study derived and validated the Quebec clinical decision tool to risk stratify emergency department patients for development of delayed hemothorax based upon consideration of patient age (> $70 \mathrm{yr}, 2$ points; 45-70 yr, 1 point), presence of a high- to mid-rib fracture (ribs 3-9, 2 points), and presence of 3 or more rib fractures (1 point). Our patient scored high-risk ( $\geq 4$ ) for delayed hemothorax upon initial ED visit. A greater suspicion for delayed hemothorax in our patient may have informed patient education, resumption of aspirin therapy, and followup to rapidly detect hemothorax and avoid lifethreatening ED presentation.

Tube thoracostomy is commonly necessary and sufficient for management of delayed hemothorax [14]. The importance of rapid recognition and evaluation of delayed hemothorax is further underscored due to the uncommon yet serious complication of retained hemothorax, with a reported incidence of 5-30\%, that largely require surgical intervention $[15,16]$. An even rarer manifestation of delayed hemothorax is the 
Citation: Chokshi T, Theodosopoulos A, Wilson E, Ysit M, Alhadi S, Ranasinghe L. A Case Report of Delayed Hemothorax Complicated by Fibrothorax. Asp Biomed Clin Case Rep. 2021 Nov 02;4(3):184-90.

Case Report

incidence of fibrothorax, reported to be found in $1 \%$ of retained hemothoraces, which also indicates surgical management with open thoracotomy [17]. Our patient's presentation of delayed hemothorax was initially intervened by VATS, which was converted to an open thoracotomy due to the presence of fibrothorax. Given the mortality often associated with these complications, delayed hemothorax should be regularly considered among critical manifestations of chest wall trauma.

\section{Conclusion}

Delayed hemothorax is an infrequently considered sequelae of chest wall trauma, however its clinical relevance is equal to or greater than that of other oft considered complications. Consideration of patientspecific factors and utilization of the Quebec clinical decision rule may better inform risk stratification for the development of delayed hemothorax, and improve patient outcomes via informed education and follow up [9]. While tube thoracostomy is often sufficient in management, the development of retained hemothorax or fibrothorax are less common complications that require invasive management [17]. The mortality associated with these complications underscores the importance of identification of delayed hemothorax.

\section{Conflict of Interest}

The authors have read and approved the final version of the manuscript. The authors have no conflicts of interest to declare.

\section{References}

[1] Émond M, Sirois MJ, Guimont C, Chauny JM, Daoust R, Bergeron É, Vanier L, Camden S, Le Sage N. Functional Impact of a Minor Thoracic Injury: An Investigation of Age, Delayed Hemothorax, and Rib Fracture Effects. Ann Surg. 2015 Dec;262(6):1115-22. [PMID: 25243544]

[2] Chang SW, Ryu KM, Ryu JW. Delayed massive hemothorax requiring surgery after blunt thoracic trauma over a 5-year period: complicating rib fracture with sharp edge associated with diaphragm injury. Clin Exp Emerg Med. 2018 Mar 30;5(1):60-65. [PMID: 29618191]

[3] Yap D, Ng M, Chaudhury M, Mbakada N. Longest delayed hemothorax reported after blunt chest injury.
Am J Emerg Med. 2018 Jan;36(1):171.e1-171.e3. [PMID: 29079373]

[4] Zeiler J, Idell S, Norwood S, Cook A. Hemothorax: A Review of the Literature. Clin Pulm Med. 2020 Jan;27(1):1-12. [PMID: 33437141]

[5] Carrillo EH, Richardson JD. Thoracoscopy in the management of hemothorax and retained blood after trauma. Curr Opin Pulm Med. 1998 Jul;4(4):243-46. [PMID: 10813242]

[6] Dogrul BN, Kiliccalan I, Asci ES, Peker SC. Blunt trauma related chest wall and pulmonary injuries: An overview. Chin J Traumatol. 2020 Jun;23(3):125-38. [PMID: 32417043]

[7] Bansidhar BJ, Lagares-Garcia JA, Miller SL. Clinical rib fractures: are follow-up chest X-rays a waste of resources? Am Surg. 2002 May;68(5):449-53. [PMID: 12013289]

[8] Misthos P, Kakaris S, Sepsas E, Athanassiadi K, Skottis I. A prospective analysis of occult pneumothorax, delayed pneumothorax and delayed hemothorax after minor blunt thoracic trauma. Eur J Cardiothorac Surg. 2004 May;25(5):859-64. [PMID: 15082295]

[9] Émond M, Guimont C, Chauny JM, Daoust R, Bergeron É, Vanier L, Moore L, Plourde M, Kuimi B, Boucher V, Allain-Boulé N, Le Sage N. Clinical prediction rule for delayed hemothorax after minor thoracic injury: a multicentre derivation and validation study. CMAJ Open. 2017 Jun 12;5(2):E444-E453. [PMID: 28611156]

[10] Plourde M, Émond M, Lavoie A, Guimont C, Le Sage N, Chauny JM, Bergeron É, Vanier L, Moore L, Allain-Boulé N, Fratu RF, Dufresne M. Étude de cohorte sur la prévalence et les facteurs de risque de complications pulmonaires tardives chez les adultes à la suite d'un traumatisme thoracique mineur fermé [Cohort study on the prevalence and risk factors of late pulmonary complications in adults following a closed minor chest trauma]. CJEM. 2013 Nov;15(6):337-44. French. [PMID: 24176457]

[11] Ho SW, Teng YH, Yang SF, Yeh HW, Wang YH, Chou MC, Yeh CB. Risk of pneumonia in patients with isolated minor rib fractures: a nationwide cohort study. BMJ Open. 2017 Jan 13;7(1):e013029. [PMID: 28087547]

[12] Chauny JM, Émond M, Plourde M, Guimont C, Le Sage N, Vanier L, Bergeron E, Dufresne M, Allain-Boulé 
Citation: Chokshi T, Theodosopoulos A, Wilson E, Ysit M, Alhadi S, Ranasinghe L. A Case Report of Delayed Hemothorax Complicated by Fibrothorax. Asp Biomed Clin Case Rep. 2021 Nov 02;4(3):184-90.

\section{Case Report}

N, Fratu R. Patients with rib fractures do not develop delayed pneumonia: a prospective, multicenter cohort study of minor thoracic injury. Ann Emerg Med. 2012 Dec;6o(6):726-31. [PMID: 22542306]

[13] Simon BJ, Chu Q, Emhoff TA, Fiallo VM, Lee KF. Delayed hemothorax after blunt thoracic trauma: an uncommon entity with significant morbidity. J Trauma. 1998 Oct;45(4):673-76. [PMID: 9783603]

[14] Molnar TF. Thoracic Trauma: Which Chest Tube When and Where? Thorac Surg Clin. 2017 Feb;27(1):13-23. [PMID: 27865322]

[15] Cohen NS, Braig Z, Collins JN. Prevalence and Management of Posttraumatic Retained Hemothorax in a Level 1 Trauma Center. Am Surg. 2018 Sep 1;84(9):e369-71. [PMID: 30269710]

[16] Morales Uribe $\mathrm{CH}$, Villegas Lanau MI, Petro Sánchez RD. Best timing for thoracoscopic evacuation of retained post-traumatic hemothorax. Surg Endosc. 2008 Jan;22(1):91-95. [PMID: 17483994]

[17] DuBose J, Inaba K, Okoye O, Demetriades D, Scalea T, O'Connor J, Menaker J, Morales C, Shiflett T, Brown C, Copwood B; AAST Retained Hemothorax Study Group. Development of posttraumatic empyema in patients with retained hemothorax: results of a prospective, observational AAST study. J Trauma Acute Care Surg. 2012 Sep;73(3):752-57. [PMID: 22929504] 